DOI: https://doi.org/10.21721/p2p.2018v5n1.p26-42

INOVAÇÃo

\title{
PAUL SINGER: A EXPERIÊNCIA DO PLANO DIRETOR DE SÃO PAULO
}

\section{Eugênia Vitória Camera Loureiro ${ }^{1}$}

PCRJ

\section{Resumo}

A contribuição de Paul Singer e sua dedicação ao tema da urbanização e desenvolvimento será abordada a partir do livro Urbanização e Desenvolvimento (SINGER, 2017), em especial o capítulo "A Luta pelo Plano Diretor Ideologia e Interesses em Jogo" (SINGER, 2017, p.147-183) onde descreve sua experiência como Secretario de Planejamento no encaminhamento de um novo Plano Diretor para a cidade de São Paulo na gestão Luiza Erundina.

Palavras-chave: Paul Singer. São Paulo. Plano Diretor. Urbanismo. Cidade.

\section{PAUL SINGER: THE EXPERIENCE OF THE DIRECTOR PLAN OF SÃO PAULO}

\begin{abstract}
The contribution of Paul Singer and his dedication to the theme of urbanization and development will be approached from the book Urbanization and Development (SINGER, 2017), especially the chapter "The Fight for the Master Plan Ideology and Interests in Play" (SINGER, 2017, p.147-183) where she describes her experience as Secretary of Planning in the direction of a new Master Plan for the city of São Paulo in the management of Luiza Erundina.
\end{abstract}

Keywords: Paul Singer. São Paulo. Master Plan. Urbanism. City.

\footnotetext{
${ }^{1}$ Graduada em Arquitetura e Urbanismo pela FAU/UFRJ. Possui mestrado e doutorado em Ciência da Informação pela Universidade Federal do Rio de Janeiro (1998 e 2005). Atualmente é analista de projetos da Prefeitura da Cidade do Rio de Janeiro.
}

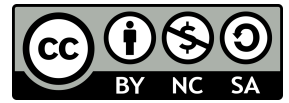

P2P \& INOVAÇÃO, Rio de Janeiro, v. 5 n. 1, Ed. Especial, p.26-42, 2018. 
A contribuição de Paul Singer e sua dedicação ao tema da urbanização e desenvolvimento será abordada a partir do livro Urbanização e Desenvolvimento (SINGER, 2017), em especial o capítulo "A Luta pelo Plano Diretor Ideologia e Interesses em Jogo" (SINGER, 2017, p.147-183) onde descreve sua experiência como Secretario de Planejamento no encaminhamento de um novo Plano Diretor para a cidade de São Paulo na gestão Luiza Erundina.

A experiência de Singer no processo de elaboração, discussão e aprovação do Plano Diretor de São Paulo constitui experiência inovadora frente aos processos e propostas privilegiados em planos anteriores, da mesma forma que as novas regras de uso e ocupação do solo buscaram mudar completamente a forma de se tratar o espaço urbano até então. A apresentação de Singer sobre a experiência realizada no início dos anos 90 aponta também o caminho para novas abordagens de sistemas de informação a partir do registro de experiências políticas.

O relato de Singer é entremeado de observações sobre a natureza política das opções, dos processos desencadeados e dos resultados alcançados. E fica evidente ao longo dessa jornada rumo a um novo Plano a assimetria existente quanto ao acesso à informação entre os diversos segmentos sociais envolvidos, refletindo os conflitos pelo uso do solo urbano. Aparece ainda com destaque o papel fundamental de um sistema de informação no acompanhamento e transparência das novas regras a serem implantadas pelo Plano.

Paulo Singer, economista, embora não nascido no Brasil, chegou em 1940 vindo da Áustria e passou a maior parte de sua vida em São Paulo, e à exceção de sua tese de doutorado, em 1966, em que abordou um estudo comparativo com outras capitais, Belo Horizonte, Porto Alegre, Blumenau e Recife, sempre se referiu principalmente a São Paulo. De fato, ele pensava poder explicar o Brasil a partir de São Paulo:

Então foi ele [Florestan Fernandes] que me propôs fazer a tese. Eram cinco cidades e eu fui trabalhando uma atrás da outra. Eu tinha muita coisa a fazer, eu tinha emprego etc. Não vivia disso. Mas eu conseguia encaixar e viajei a essas cidades. Foi a primeira vez que fiz pesquisa de campo, por assim dizer; foi uma alegria para mim. A cada cidade visitada, fazia e entregava o texto a ele, que depois dava sua opinião. Praticamente, ele sempre gostou dos textos. Não me lembro de ter me pedido mais alguma coisa. O último foi São Paulo, acho, porque ela é o centro da urbanização brasileira. Quando analisei São Paulo era ela em relação às outras cidades. (SINGER, 2017, p. 199)

Pensar apenas São Paulo não é exclusivo de Paul Singer, mas de muitos intelectuais paulistas. Entretanto é o contrário do que acontece em outras capitais como o Rio de Janeiro ou Recife onde se pensa até mais o Brasil. E essa característica é vista muitas vezes não como 
virtude, mas como algo que precisaria ser equilibrado talvez com mais pensar local de forma a enfrentar os desafios colocados pelos problemas de desenvolvimento.

Seja como for, isso acontece por motivos que talvez possam ser identificados. Quem sabe o chamado "espírito de 32" paulistano? Pensamento que está na base da cultura paulista juntamente com a ideia de que "São Paulo não pode parar" ou ainda "São Paulo é a locomotiva do Brasil”.

O pensamento de Singer a esse respeito, além de presentes no capítulo e do livro já citado, aparece também nos conteúdos de duas entrevistas. Uma delas concedida à Marcelo Justo ao final do livro e a outra reproduzida no site da editora Boitempo e ainda na apresentação de Marcelo Justo para o livro. ${ }^{2}$

Ao analisar o desenvolvimento capitalista no país, Singer o acompanha pelo pulso - a partir da cidade de São Paulo e sua "metropolização". Considerava que São Paulo tinha se tornado o centro do livre mercado, e ele se perguntava "porque especificamente São Paulo, a cidade dos estudantes e da garoa, e não o Rio de janeiro que havia se industrializado antes, era a capital federal, tinha mais recursos, era maior que São Paulo etc.” (SINGER,2017, P. 200)

Ao analisar o desenvolvimento capitalista no país, Singer o acompanha pelo pulso - a partir da cidade de São Paulo e sua metropolização" . Considerava que São Paulo tinha se tornado o centro do livre mercado, e ele se perguntava "porque especificamente São Paulo, a cidade dos estudantes e da garoa, e não o Rio de janeiro que havia se industrializado antes, era a capital federal, tinha mais recursos, era maior que São Paulo etc."

Talvez uma resposta para essa pergunta estivesse na utilização do mito do homem cordial de Sérgio Buarque de Holanda, aplicado para o caso do Rio de Janeiro e São Paulo, onde a primeira encarnaria a cidade das emoções e a segunda a cidade do trabalho. O que por sua vez indicaria que a opção por São Paulo não teria sido resultado da atuação do livre mercado mas sim da ação consciente de um conjunto de forças políticas e econômicas. Nada mais de acordo com o "espírito de 32" quando São Paulo empreendeu uma assim chamada revolução em 1932 contra as medidas tomadas pelo governo federal sediado no Rio de Janeiro.

Contudo, não se trata aqui de discutir o papel de São Paulo no desenvolvimento e na economia do país, mas de buscar contextualizar o pensamento de Paul Singer. Cláudia Viscardi (2012), historiadora, chama a atenção para o excepcionalismo do estado bandeirante: republicanismo histórico e sólido, cafeicultura, industrialização, finanças, transportes,

\footnotetext{
${ }^{2}$ https://blogdaboitempo.com.br/2018/04/18/paul-singer-trajetoria-critica-margem-esquerda-entrevista/
} 
imigração em massa, crescimento urbano e populacional. Tudo isso foi conjugado de modo peculiar, mas, segundo ela, não constituiria modelo, e sim experiência.

De uma forma geral autores/intelectuais paulistas não se veem como experiência o que implicaria considerar o outro ou outros como detentores de experiências igualmente válidas e dignas de estudo e interpretação. Isso fez parte do contexto em que Paul Singer viveu e trabalhou, e pode oferecer uma hipótese para justificar um certo paulicentrismo cultivado por ele.

Os acontecimentos relatados por Singer no processo de discussão de um novo Plano Diretor para São Paulo, os interesses em jogo e as propostas do poder público, compõem uma reflexão brilhante que não deixou de apontar com clareza os limites desse instrumento tão caro à maioria dos arquitetos e urbanistas.

Planos Diretores sempre despertam grandes esperanças como instrumentos de ordenação, regulação e racionalização do desenvolvimento feral das cidades. Além disso, esperava-se que promovessem equidade ao proporcionar aos marginalizados, que nunca haviam podido ganhar o bastante para adquirir no mercado moradias decentes, acesso à terra. Tais expectativas foram particularmente fortes durante o regime militar, quando a lei exigia de cada município a aprovação de um Plano Diretor para poder receber créditos subsidiados no Banco nacional da Habitação (BNH), a fim de construir moradias e sistemas de água e esgoto.

O primeiro Plano Diretor de São Paulo surgiu em 1971, no auge da ditadura militar e do "milagre brasileiro". O crescimento da economia era extraordinário e havia recursos abundantes para investir na infraestrutura urbana. Mesmo assim, o plano Diretor de 1971 nunca se tornou realidade, (...) (SINGER, 2017, p.148)

Paul Singer credita o fracasso do PD de 1971 à brutal reversão de expectativas que aconteceu a partir de 1974 com o declínio do "milagre", uma vez que a rede de vias expressas prevista pelo Plano e sobre a qual se baseou a lei de zoneamento jamais foi construída. A partir de 1981 o país mergulhou em recessão devido ao segundo choque do petróleo. Singer faz-se então a pergunta se o Plano Diretor poderia ter previsto essa reversão e produzido instrumentos para mitigar seus efeitos. Para ele isso seria ir contra a própria noção de Plano, uma previsão de um desenvolvimento melhor e a crença em um futuro urbano manejável. Segundo ele, “[...] sobretudo expressavam a capacidade da comunidade politicamente organizada". E ele reflete: “[...] a comunidade possui essa capacidade?” (SINGER, 2017, p. 149)

Mesmo assim, como diz Singer, "a fé nos planos diretores continuou intensa nos anos 1980” (SINGER,2017, p.149). O prefeito Mario Covas (1983-1985) mandou fazer um, mas enviou à Câmara só no final do mandato e nem chegou a ser apreciado. Jânio Quadros (19861988) que também foi engavetado, mas acabou sendo aprovado pelo instituto do decurso de prazo. Esses planos, no entanto, se concentravam em propor diretrizes a "lei resultante acabava 
sendo um extenso enunciado de intenções quase sem medidas substantivas a serem implementadas'(SINGER,2017, p.149). Para Singer os verdadeiros crentes nos Planos Diretores eram os urbanistas. Os únicos, segundo ele.

Quando Singer assumiu a Secretaria de Planejamento - SEMPLA - notou que as considerações acerca de um novo plano diretor estavam longe de ser consenso entre os técnicos. O grupo liderado pela arquiteta urbanista Raquel Rolnik, relata ele, venceu a disputa afirmando o que não desejava mais uma série de enunciados de princípios e imagens de futuro, mas medidas implementáveis para enfrentar a crise vivida por São Paulo no aqui e agora.

Acabei concluindo rapidamente que o governo do PT tinha que apresentar um projeto de Plano Diretor que produzisse resultados. Ele teria que anunciar a reforma urbana de modo que, por exemplo, os favelados recebessem a posse legal do solo urbano que ocupavam e os pobres ganhassem acesso ao solo e aos serviços urbanos básicos. Ele deveria distinguir-se de seus predecessores pelo fato de todos os objetivos propostos para a cidade terem medidas implementáveis como base. (SINGER, 2017, p.150)

Havia sido promulgada a Constituição de 1988 e com ela o artigo 182 que dependia de regulamentação ${ }^{3}$. E com ele ficou estabelecido que a política de desenvolvimento urbano executada pelo poder público municipal, conforme diretrizes gerais fixadas em lei, tem por objetivo ordenar o pleno desenvolvimento das funções sociais da cidade e garantir o bem-estar de seus habitantes. Esse artigo foi uma vitória para os movimentos sociais, os que lutavam por uma reforma urbana e uma cidade mais justa. Mas também continha elementos de adiamento ao precisar de regulamentação. Por outro lado, o Plano Diretor se fazia necessário pois:

[...] ]em cada cidade certas áreas devem ser protegidas do adensamento e mesmo da ocupação, como as áreas de mananciais, as áreas verdes e as áreas sujeitas à erosão. A reforma urbana deve ser aplicada nas áreas que o Plano Diretor defina como adensáveis, tendo em vista a evolução global da cidade. (SINGER, 2017,p.152).

Depois da Constituição Federal foram aprovadas em 1989 as constituições dos Estados e em 1990, as constituições dos Municípios, denominadas Leis Orgânicas. Uma das exigências contidas na lei Orgânica de São Paulo foi a de elaborar um Plano Diretor até 5 de fevereiro de 1991. Singer lamentou o fato da Lei Orgânica não fixar prazo para o Legislativo para aproválo (SINGER, 2017, p.152).

\footnotetext{
${ }^{3}$ A regulamentação do artigo 182 só aconteceria 13 anos depois com o Estatuto da Cidade - 10.257 de 10 de julho de 2001, que regulamenta o capítulo "Política urbana" da Constituição brasileira. Seus princípios básicos são o planejamento participativo e a função social da propriedade.
} 
O primeiro passo a partir daí foi iniciar uma coleta, compilação e análise de dados atualizados sobre a cidade. Os resultados dessa atividade que durou cerca de um ano foram reunidos no livro São Paulo: crise e mudança (ROLNIK, et alii, 1991) .

Alguns resultados merecem destaque e, embora se refiram apenas como características específicas de São Paulo de fato podemos dizer, a partir do que sabemos hoje dos fenômenos econômicos e da globalização, que são comuns a todas as grandes cidades brasileiras e até fora do Brasil. Uma dessas características por exemplo é a predominância da economia de serviços em detrimento da economia industrial. O crescimento das favelas e assentamentos de baixa renda passaram a ser tendência nas diversas cidades do país como consequência de políticas que na prática promoviam a desigualdade urbana.

Outro resultado notável foi de que os assentamentos ilegais - cortiços, favelas e loteamentos clandestinos - representavam $65 \%$ de todos os assentamentos. (...) Um dos principais propósitos do projeto de Plano Diretor que estávamos elaborando seria mudar uma situação em que apenas o terço economicamente privilegiado da população pode usufruir dos benefícios garantidos pela legislação urbanística. (SINGER, 2017, p.154-155)

Outra avaliação que chamou atenção da equipe técnica da Sempla foi a especialização entre zonas da cidade, fazendo com que as atividades econômicas predominassem em áreas onde não predominava ou não era possível o uso residencial, o que resultava em ociosidade da infraestrutura em períodos do dia. A ideia então seria promover uma maior mistura de usos de forma a reduzir desperdício causado por essa alternância.

Outra consequência da especialização espacial numa vasta metrópole como São é que obriga milhões de trabalhadores a se deslocarem diariamente por longas distâncias, o que sobrecarrega os sistemas de transporte de massa durante determinados períodos (nas horas de pico) e os deixa subutilizados no resto do tempo. (SINGER, 2017, p.155)

A título de comentário, é possível considerar que o peso da mistura de usos nos deslocamentos é condicionado também, nas cidades brasileiras, pela desigualdade de renda frente à valorização e preço da terra. Hoje a chance de moradia para os segmentos de mais baixa renda é avançando pelas franjas cada vez mais distantes do centro urbano. Quanto menos infraestrutura, mais barata a terra e, quanto mais "infraestruturada", mais cara a terra e mais inacessível para esses segmentos, sem pesados investimentos públicos como forma de subsídio. De fato, o maior custo dos aglomerados urbanos nas cidades brasileiras é proveniente da desigualdade social. 
A ênfase no pedestre que adquire relevância atualmente não trata do problema da desigualdade urbana. Outro aspecto importante é a ênfase na concentração/adensamento ao longo dos corredores de transporte e tráfego. Mas a cidade compacta preconizada nos dias de hoje como ideal, sem medidas e financiamento adequados, pode se tornar uma cidade cara e para poucos.

Singer, contudo, ao se deparar com o crescimento de $25 \%$ para $36 \%$ nas viagens feitas a pé entre 1977 e 1987 acabou por associar esse fato com a deficiência no fornecimento de serviços públicos.

Era inegável, no entanto, que as frotas de ônibus, que respondem pela maioria dos deslocamentos por transportes de massas, não tinham sido expandidas desde 1970, o que explica o fato de serem insuficientes para atender a demanda. A mesma insuficiência foi constatada em relação aos sistemas de água e de esgotos e à rede de distribuição de energia elétrica. A falta de investimentos nesses serviços era a principal causa de sua crescente incapacidade de atender às demandas do público. (SINGER, 2017, p.156)

A precariedade ou ausência de investimentos e a restrição de crédito aos governos locais, segundo Singer, estavam na raiz desses problemas. O que estava em jogo e ainda está é o financiamento das cidades ${ }^{4}$. Por isso o novo Plano Diretor deveria conter um sistema completamente diferente de regras de criação de espaço construído como resultado do uso e ocupação do solo urbano. O principal critério de permissão ou não dessa criação seria a "disponibilidade de infraestrutura urbana a ser utilizada em função do adensamento provocado" (SINGER, 2017, p.156).

O objetivo do sistema a ser implantado era promover de um lado a acumulação de capital na cidade pela flexibilização das restrições impostas pelo zoneamento, para Singer "arbitrariamente impostas" pela legislação. De outro reunir recursos para promover a construção de moradia social, obras de urbanização e infraestrutura, além de investimento nas áreas verdes da cidade. Em cada região da cidade seria medida a infraestrutura ociosa ou disponível e calculada a construção necessária para utilizá-la plenamente. Esse diferencial comporia o "estoque de área edificável."

\footnotetext{
${ }^{4}$ Naquele momento, como agora, não é possível pensar em recursos originários de financiamentos. Estes estavam fechados para as municipalidades por conta do chamado déficit público. Situação não muito diferente de agora com a Emenda Constitucional 95/2016 que tem por objetivo de equilíbrio das contas públicas por meio de um rígido mecanismo de controle de gastos, a EC do teto de gastos públicos foi aprovada depois de muita discussão entre os senadores. De acordo com o texto, o teto para 2017, primeiro ano de vigência, seria definido com base na despesa primária paga em 2016 (incluídos os restos a pagar), com a correção de 7,2\%, a inflação prevista para este ano. A partir de 2018, os gastos federais só poderão aumentar de acordo com a inflação acumulada conforme o Índice Nacional de Preços ao Consumidor Amplo (IPCA).
} 
Esses recursos viriam da "troca" por contribuições de área edificável na zona adensável que formariam um fundo de urbanização" (SINGER, 2017, p.160). A formação do Fundo se daria a partir do estabelecimento de um índice unitário igual a 1 para toda a cidade. Quem quisesse construir a mais pagaria uma contrapartida ao Fundo.

Se o lote estivesse situado em uma zona não adensável só seria possível construir sem ônus e uma vez a área do terreno. Se estivesse localizado em área adensável seria possível construir além da uma vez já permitida, também a diferença correspondente a parte do estoque edificável. Além disso só projetos residenciais acima de $40 \mathrm{mil} \mathrm{m}^{2}$ e comerciais acima de 20 mil $\mathrm{m}^{2}$, em função de seu grande impacto sobre o ambiente urbano continuariam sendo objeto de estudos específicos.

A partir dessa simplificação esperava-se obter ainda outro resultado: a de redução da especialização territorial que significa uma maior mistura de usos, beneficiando a população trabalhadora ao evitar que perdesse horas do dia em deslocamentos casa-trabalho-casa e ao mesmo tempo fazendo um uso complementar da infraestrutura. Para alcançar esse objetivo foram definidos dois estoques de área edificável: um de edificações comerciais e outro de edificações residenciais.

O adensamento governado pela alienação onerosa de área edificável deveria favorecer a edificação residencial nas subzonas predominantemente comerciais. Isso reduziria as distâncias entre moradia e local de trabalho."

Cumpre lembrar que no passado São Paulo era um centro predominantemente industrial e que parte das indústrias era bastante poluidora, o que exigia a separação espacial entre elas e as áreas residenciais. Atualmente ocorrências dessa espécie são cada vez mais raras em São Paulo e é claro na medida em que ainda existem devem ser afastadas das áreas de moradia. Mas como vimos São Paulo se especializa cada vez mais em atividades de serviços e industriais de tecnologia avançada que não são poluidoras. Por isso, a atual segregação entre locais de trabalho e locais de moradia deixa de ter qualquer justificativa, a não ser o preconceito contra morar em zonas de atividades comerciais. (SINGER, 2017, P.160)

É preciso lembrar igualmente que esse fenômeno da desindustrialização no Brasil não ocorreu apenas em São Paulo, mas no mundo inteiro, e também nos principais centros do país. Outro fenômeno resultado da globalização, o fordismo, de produção para todos e que necessitava de muito espaço para produzir, foi substituído pelo toyotismo de produção just in time ou de acordo com a demanda que poderia se adaptar a locais menores e menos poluição.

Mas com as mudanças na produção surgiram outras formas de poluição como imensos galpões destinados a armazenagens trazendo movimento intenso de caminhões, e outras grandes instalações como shoppings, supermercados, igualmente geradores de tráfego. A 
dispersão da localização industrial e das grandes instalações, tornando inútil a segregação espacial de outrora, também foi possível por conta dos avanços da tecnologia e dos sistemas de informação.

Um sistema de planejamento e um sistema de informações seriam criados e teriam como principal objetivo o controle e atualização dos estoques edificáveis que estariam em permanente mudança e os respectivos valores de aquisição. Além disso possibilitaria a disponibilização de informações a todos os interessados.

[...] o órgão central de planejamento manteria um sistema de informações para fornecer o tempo todo dados utilizados sobre os estoques de área edificável, por uso e por zona, compreendendo as diversas fases de sua utilização e disponibilidade, sobretudo a infraestrutura, sua capacidade e programas de sua ampliaçãoe sobre as receitas e despesas do fundo de urbanização. Essa obrigação permanente de informar permitiria uma ação fiscalizatória eficaz por parte dos cidadãos interessados. Além disso todos poderiam dispor das informações relevantes quanto às possibilidades de valorização ou desvalorização de imóveis nas subzonas adensáveis, em vez de constituir privilágio de uns poucos "dentro" da administração. (SINGER, 2017, p.162)

A título de simplificação à exceção ao exercício das novas regras de uso e ocupação do solo impostas pelo novo Plano Diretor seriam as Zonas de Interesse Especial. Essas zonas em razão de sua unidade ou de seu caráter estrutural ou de sua importância histórica, paisagística, ambiental ou cultural seriam objeto de regulamentação específica. de forma a capacitar o poder público no enfrentamento de necessidades específicas em função de peculiaridades sociais, culturais ou físicas nessas porções do território.

As mais importantes delas para nós eram as ZEIS - zonas especiais de interesse social - que deveriam ser um dos principais instrumentos de integração das camadas especialmente marginalizadas. (...) Propunham que o Executivo elaborasse plano de urbanização para as ZEIS de modo a fixar e normalizaras condições de moradia da grande massa de baixa renda, relegada a assentamentos desumanos e que promovesse a regularização fundiária (...). Propunha também a participação do setor privado nos programas de habitação popular para viabilizá-lo, dispunha que fosse gratuita a outorga de autorização para construir área superior à do coeficiente único, desde que destinada a habitações de interesse social. (SINGER, 2017, p.164)

Mas Singer considerava fundamental a obtenção do o maior apoio possível à proposta, de forma que logo as consultas a grupos de interesse para novas ideias, sugestões e convencimento passaram a ocupar o centro de interesse e atividade.

Contudo a maior parte dos grupos de interesse, segundo Singer, não tinha noção e não fazia ideia de como as propostas contidas no projeto de Plano Diretor os afetavam.

Somente os representantes de arquitetos, incorporadores, construtores, corretores de imóveis e semelhantes estavam motivados a gastar tempo e energia com uma questão tão especializada aparentemente quanto um Plano Diretor. Essas associações 
profissionais e empresariais tendiam a representar antes os interesses das classes proprietárias do que das dos pobres. O que na Sempla precisava era a participação maior de movimentos sociais, sobretudo dos que falavam pelos sem-teto, favelados, cortiçados e compradores de terrenos em loteamento clandestino. (SINGER, 2017, p.166)

Era preciso trazer para a participação os segmentos mais interessados nas mudanças que na avaliação da equipe técnica Sempla eram mais ligados aos movimentos sociais: sem-teto, favelados, cortiçados e compradores de terrenos em loteamentos clandestinos, por exemplo. Mesmo assim apesar dos esforços empreendidos a participação desses segmentos continuou pequena.

A despeito de todo o tempo investido no levantamento e processamento de informações e análises das quais participaram técnicos de grande parte dos diversos órgãos municipais, embora fosse contribuição de grande valia, não tinha o condão de alinhar necessariamente seus órgãos de origem ao projeto do novo Plano Diretor.

Esses resultados foram apresentados com pompa e circunstância no Teatro Municipal de São Paulo com a presença da Prefeita Luiza Erundina autoridades, membros do legislativos e entidades dos movimentos sociais.

Numerosas entidades seriam consultadas: universidades e centros de pesquisa; empresas de serviços públicos; sindicatos de trabalhadores e de empresários; movimentos de favelados, cortiçados e sem-teto; sociedades de amigos de bairro e associações de moradores; e, por fim, mas não por último, partidos políticos. Além das audiências, debates com vereadores seriam realizados sobre os principais temas do Plano Diretor. Desejava-se assim mobilizar todos os setores da sociedade civil para que o futuro Plano Diretor resultasse de ampla troca de ideias, sem excluir qualquer interlocutor relevante. (SINGER, 2017, p.167)

Contudo toda essa movimentação se trouxe apoio dos segmentos mais progressistas da sociedade às novas regras a serem implementadas pelo Plano Diretor, também trouxe a oposição de empresários, comunidades de empresários e conservadores que preferiam ver as áreas mais bem servidas de infraestrutura sem mais adensamento, conforme o zoneamento vigente então. Os principais setores da mídia deram apoio evidente a esses segmentos. Abrir uma negociação fazia-se necessário.

A principal objeção do segmento empresarial da cidade, naquele momento como até hoje, era a redução do coeficiente de aproveitamento do terreno a 1. E argumentavam que o preço do terreno poderia não cair. Além disso não concordavam com a transferência para o governo no sentido da constituição do Fundo, mesmo que o objetivo do Fundo fosse o empregar 
o arrecadado para construção de moradias, incluindo moradias de interesse social, e que isso demandaria serviços de construção. Era uma questão ideológica.

A percepção ideológica estava impedindo os representantes de arquitetos, construtores e incorporadores de enxergar com isenção onde estavam seus interesses materiais. Poder-se-ia indagar se o novo sistema de uso e ocupação do solo encontraria tanta resistência se tivesse sido formulado por um governo conservador. $\mathrm{O}$ fato de o governo de Erundina ser de esquerda deve ter provocado todo tipo de receios e mal-entendidos a respeito de uma proposta que já era prática rotineira na Europa Ocidental. (SINGER, 2017, p.168)

Nosso objetivo mais importante era redistribuir renda e reverter o crescente abismo entre ricos e pobres pelo alívio das piores carências do trabalhador. Tal objetivo requer que o investimento de capital faça crescer o rendimento global e que uma parcela crescente deste financie serviços públicos e a aquisição privada de bens pelos trabalhadores e suas famílias. [...] Nossa proposta de Plano Diretor visava apenas eliminar privilégios - os direitos gratuitos de construir acima de CA igual a 1 -e restrições indevidas ao direito de construir - impostas pelo atual zoneamento. (SINGER, 2017, p.168)

O esperado era que essa proposta desagradasse ou mesmo trouxesse prejuízo a uns poucos proprietários de terrenos onde o CA era superior. De qualquer forma isso poderia ser equilibrado por um grande fluxo de investimentos em construção residencial e não residencial e apenas parte disso seria canalizado para o fundo de urbanização. O restante seria canalizado para reprodução do próprio capital. Tempo esgotado para o envio da proposta de PD a Câmara de Vereadores ficou decidido que enviariam a proposta por inteiro tendo em vista que acabaria por sofrer ajustes por conta do processo de negociação que se instalaria.

A única concessão considerada importante ser feita foi a de um período de transição de 6 meses após a promulgação do Plano Diretor para a apresentação de projetos para os terrenos com CA maior do que 1 . Nos 6 meses seguintes apenas 3/4 da área total a construir com CA maior que 1. E assim sucessivamente por um período total de 2 anos, quando então o total a construir seria com CA igual a 1, à exceção das áreas adensáveis onde seria possível adquirir direito de construir com CA acima de 1. A implantação do coeficiente de aproveitamento do terreno igual a 1 estava sendo vista como um processo.

No entanto os empresários ligados ao desenvolvimento queriam prazo de 5 a 10 anos o que adiaria ou mesmo poderia inviabilizar a implantação da proposta do Plano Diretor e seus resultados em termos de investimentos para benefício da cidade.

Na data prevista pela Lei Orgânica a proposta de Plano Diretor foi enviada à Câmara de Vereadores. Apesar de todo o esforço empreendido pelos técnicos da prefeitura, toda a discussão esclarecedora levada adiante nos diversos segmentos sociais e da cobertura da 
imprensa, a questão ainda era: qual seria na prática o efeito para o cidadão comum, o que ele ganharia?

Segundo Singer seria preciso uma resposta muito honesta a essa pergunta e o que havia de fato havia era:

[...] uma longa lista de condicionais: se houvesse disposição do setor privado de investir, se as novas construções fossem localizadas nos lugares certos, se novos empregos fossem criados em áreas hoje predominantemente residenciais, e assim por diante. (SINGER, 2017, p.171)

Ao longo de todo o texto Paul Singer faz uma avaliação política do processo de discussão do Plano Diretor e um paralelo com a aprovação da Constituinte de 1988, as constituintes estaduais de 1989 e as leis orgânicas municipais de 1990:

Embora muitos grupos de interesse tivessem se mobilizando para disputar questões concretas (a maioria das quais sequer pertencia ao âmbito constitucional), as principais regras que governavam a vida institucional foral decididas sem qualquer pressão do movimento popular. [...] Era o caso Plano Diretor [...] que consistia basicamente em um conjunto de novas regras que governariam a produção, a ocupação e o uso do espaço urbano. (SINGER, 2017, p.171)

Talvez tivesse sido possível defender alguns resultados concretos que poderiam vir das novas regras como o número de moradias populares que poderiam ser construídas ou as melhorias que se tornariam possíveis no transporte público. Mas a equipe técnica considerou que essa iniciativa poderia ser confundida com um exercício banal de futurologia e não quis seguir por esse caminho. E Singer observa:

Mas, assim agindo, acabamos despertando os receios dos que poderiam sofrer perdas e dos que interpretavam o projeto equivocadamente, e não conseguimos mobilizar os que tinham a ganhar com o novo plano. (SINGER, 2017, p.172)

Ao final doze entidades empresarias assinaram um manifesto contrário ao projeto, embora a maioria elogiasse sua qualidade técnica. Essas entidades se posicionaram contra o novo conjunto de regras de uso e ocupação do espaço urbano.

Os empresários buscaram um ex-prefeito de São Paulo dos anos 70 para atuar como porta-voz. Adepto de ideias que identificavam o crescimento de São Paulo como o resultado da atração de emigrantes, defendia que era preciso impedir esse crescimento e considerava que as propostas de regularizar e urbanizar favelas e prover moradias baratas para os segmentos mais pobres iriam atrair milhares de imigrantes para a capital.

O debate sobre o Plano Diretor da cidade também chegou à universidade. E lá também surgiram incompreensões. 
A principal crítica levantada nesse debate foi a de que o Plano Diretor não era um "plano", pois não mensurava nem projetava cada uma das necessidades da cidade nem propunha medidas para satisfazê-las. [...] para eles um Plano Diretor era um exercício intelectual. Pouco lhes importava se o governo municipal teria os meios para cumprir as tarefas definidas pelo plano ou se haveria possibilidade de induzir o capital privado a fazer inversões que o plano considerava necessário. (SINGER, 2017, p.173)

Com o projeto em tramitação na Câmara de Vereadores, esperava-se o início das negociações, mas isso não aconteceu. Além da proposta de um novo Plano Diretor, estavam em tramitação outras propostas de interesse do Executivo. Fato é que por conta disso mesmo nada acontecia, dado que era essa a posição da oposição que acabara de formar maioria incluindo a presidência da mesa. Nesse contexto a oposição preferia engavetar do que discutir, mesmo porque o Plano Diretor e o Código de Edificações que também estava em pauta exigiam quórum qualificado. E como se não bastasse a própria bancada situacionista tinha outras prioridades.

Quando Paul Singer descreve de forma assim pormenorizada os eventos que cercaram tanto antes ou depois da tramitação da proposta do Plano Diretor de São Paulo não tinha como saber à época que com algumas variações o mesmo tipo de processo aconteceria nas cidades e capitais onde foram elaboradas propostas de Plano Diretor por governos progressistas.

Mas tendo em vista a grande dificuldade de encaminhamento da proposta de Plano Diretor na Câmara de vereadores, Singer e a equipe da Sempla decidiram tentar iniciar um processo de negociação fora dela, de forma a tentar influenciar positivamente o processo, a partir dos especialistas que tinham críticas ao zoneamento existente muitas das quais partilhadas pela equipe técnica do Plano, e o fato de serem:

[...] os peritos de confiança dos maiores incorporadores e investidores e estavam ligados a todos os partidos oposicionistas, dos mais conservadores aos autodesignados social democratas. Além disso, as relações pessoais desses arquitetos com os urbanistas do meu staff eram surpreendentemente boas. Cada lado respeitava a competência profissional e o amplo conhecimento teórico e prático do outro. (SINGER, 2017, p.174)

Para Singer os encontros realizados entre os dois grupos não eram propriamente secretos, mas podiam ser chamados de confidenciais. A ideia era a de tentar chegar a uma proposta do que poderia ser considerado consenso. E realmente chegaram a vários consensos sobre uso do solo, priorização do transporte público, expandir a oferta de moradias novas para os extratos de renda mediana do mercado formal, assegurar recursos para investimentos em habitações de interesse social, até sobre os instrumentos não foi difícil chegar a um consenso. Mas aí veio a surpresa: 
[...] nossos oponentes impuseram uma limitação: nada no plano Plano Diretor poderia ser diretamente aplicável. [...] cada provisão teria que depender de especificação posterior mediante lei ordinária. [...] de acordo com a imposição do outro lado, da qual não conseguimos demovê-lo, o Plano Diretor diria muitas coisas que queríamos, mas seria meramente declaratório, sem qualquer efeito imediato sobre o uso e a ocupação do solo. (SINGER, 2017, p.176, grifo no original)

Não tendo alternativa à vista, Singer e a equipe do novo Plano Diretor considerou que:

[...] seria melhor ter um plano apenas declaratório, que ao menos apresentaria novas ideias alguma chance de serem ratificadas por legislação ordinária, do que ficarmos com nada exceto o plano natimorto de Jânio Quadros. (SINGER, 2017, p.176)

Entre as diretrizes da nova política de uso do solo consensuada havia as seguintes:

Ajustamento do uso e da ocupação do solo ao potencial da infraestrutura e do meio ambiente;

Criação de mecanismos para permitir aumento de investimentos da infraestrutura urbana, vias públicas, áreas verdes e habitação de interesse social mediante empreendimentos especiais como contrapartida de mudanças em parâmetros de uso e ocupação do solo;

Revisão futura do zoneamento à luz da criação de propostas de duas zonas, uma adensável e outra não adensável;

Foram mantidas as zonas especiais de interesse e duas novas foram adicionadas: uma em que o adensamento seria encorajado e outra para a realização de operações urbanas.

Foram criados estoques de área edificável sob o nome de "reservas edificáveis";

Reservas edificáveis definidas como "a área total que pode ser construída numa zona existente ou parte dela, acima do CA máximo previsto por lei."

A reserva edificável seria estipulada por lei, diferenciada por uso residencial e não residencial e determinada pelo potencial do sistema viário, da infraestrutura existente, tendências locacionais dos diversos usos do solo e das políticas de desenvolvimento urbano;

A área edificada poderia exceder o CA máximo desde que reservas edificáveis estivessem disponíveis: o valor correspondente à área acima do CA seria pago e os fundos resultantes seriam aplicados à infraestrutura urbana, ao sistema viário, a novas áreas verdes e habitações de interesse social. (SINGER, 2017)

É importante observar que uma nova concepção de administrar o solo urbano conseguiu ser pactuada mas não o fim do direito gratuito de construir quando o índice de aproveitamento fosse maior do que 1. Pelo contrário, não só os índices em vigor foram mantidos como se tornou possível adquirir espaço adicional das reservas edificáveis para construir acima do CA atual. O curioso para Singer é que o projeto resultante desse acordo manteve inclusive o índice máximo igual a 4 em vigor, mesmo no caso de espaço adicional adquirido. Para a equipe técnica do Plano Diretor não precisaria haver essa limitação defendida pelos empresários que alegavam não ser desejável um adensamento excessivo. A equipe do plano estava mais preocupada com a subutilização da infraestrutura e com os cidadãos que careciam de habitações adequadas. 
Os urbanistas que representavam a Sempla eram contrários a restrições quantitativas gerais do direito de construir porque elas não podem deixar de ser arbitrárias. Em muitos casos específicos, essas restrições se mostram sem sentido ou até contraproducentes, o que faz surgir emendas que abrem exceções. Com o passar do tempo, o acúmulo de casuísmos torna a regulamentação muito complexa, acessível apenas a especialistas, em detrimento do cidadão comum, obrigado a recorrer aos primeiros para encontrar o caso em que se encaixam suas necessidades. (SINGER, 2017, p.178)

Singer concluiu que um plano não pode dar conta de todas as especificidades e que o melhor seria ter gerais flexíveis e confiar sua aplicação a órgãos compostos por representantes do governo e dos principais setores da sociedade civil.

Contudo faltava ainda uma questão referente às áreas doadas ao poder público para construção de equipamentos sociais em loteamentos e que tinham sido ocupadas por favelas. Para os empresários essas áreas públicas doadas não poderiam ser objeto de alienação. Por outro lado, a equipe técnica não concordava com a remoção pura e simples dos moradores. De forma que não houve acordo possível sobre o tema e a solução foi delegar o exame da questão à lei específica.

Tendo o acordo sido firmado parecia agora não haver mais empecilhos para a aprovação. Mas não foi o que aconteceu. Uma nova oposição surgiu, tanto à direita quanto à esquerda. A mais resistente vinha dos que deveriam apoiar o plano, mas ficaram insatisfeitos com o resultado proveniente do acordo. E era preciso compreender o contexto um pouco mais geral das eleições municipais ainda naquele ano. A Comissão de Assuntos Urbanos chamou diversas audiências públicas para ouvir os interessados cujas discussões se prolongaram por todo o primeiro semestre e se sabia que não haveria discussão no segundo, uma vez que a agenda eleitoral tomaria todo o tempo.

Segundo Singer não havia esperanças de se alcançar algum consenso a tempo de se submeter um projeto de Plano Diretor à Câmara dos Vereadores e ser aprovado.

A experiência do Plano Diretor aqui relatada por Paul Singer (e a equipe) com uma riqueza impressionante de detalhes e honestidade mudou toda uma forma de conceber, legislar e decidir sobre as cidades brasileiras.

O Estatuto da Cidade Lei 10.257 de 10 de julho de 2001 que regulamenta o artigo 182 da Constituição tornou obrigatória a elaboração de planos diretores para cidades com mais de 20 mil habitantes, além de introduzir outros dispositivos legais como a outorga onerosa do direito de construir. Em 2003 foi criado o Ministério das Cidades que financiou e montou o Conselho Nacional das Cidades com representação paritária dos diversos segmentos que 
- INOVAÇÃo

representam os interesses em jogo nos aglomerados urbanos e impulsionou o processo de consulta e participação popular por meio da realização periódica da Conferência Nacional das Cidades precedida pelas Conferências Estaduais e Municipais.

Em 2015, segundo levantamento do IBGE, 2.786 das 5.572 cidades brasileiras ou 50\% tinham Plano Diretor para orientar as políticas públicas no espaço urbano. Em 2006 eram menos de 15\%. E 691 municípios estavam em fase de elaboração de um Plano Diretor. 


\section{REFERENCIAS}

ROLNIK, Raquel, et alii. São Paulo, crise e mudança. São Paulo: Prefeitura de São Paulo, Brasiliense, s.d.

SINGER, Paul. Urbanização e Desenvolvimento. Belo Horizonte: Autêntica Editora/ fundação Perseu Abramo, 2017. (Coleção Pensadores do Brasil: do tempo da ditadura ao tempo da democracia).

SINGER, Paul. A Luta pelo Plano Diretor Ideologia e Interesses em Jogo. In: SINGER, Paul. Urbanização e Desenvolvimento. Belo Horizonte: Autêntica Editora/ fundação Perseu Abramo, 2017. (Coleção Pensadores do Brasil: do tempo da ditadura ao tempo da democracia)

VISCARDI, Cláudia. O teatro das oligarquias: uma revisão da "política do café com leite". Belo Horizonte: Fino Traço, 2012. 